\title{
Morphological and genetic variations of the freshwater leech, Hirudinaria spp., in Peninsular Malaysia
}

\begin{abstract}
In this study the genetic diversity of local freshwater leeches (Hirudinaria spp.) was inferred using mtDNA COI gene analysis and compared with the gross external variations of 26 freshwater leech specimens obtained from the wild and leech farms. Based on a neighborjoining tree generated from $516 \mathrm{COI}$ base sequences, four distinct clades of Hirudinaria were seen with interspecific genetic divergence in the range of 7.6ï14.5\%. The external morphological variations based on the presence of stripes, location of gonopores, and anus separated the samples into four morphologically distinct groups matching the four clades obtained from the molecular data. Two black stripes at the ventral region were observed only in specimens found clustered with clades that contained the GenBank-reported $\mathrm{H}$. manillensis, whereas the brown or dark green coloration without stripes on the ventral region was seen in samples that clustered with $\mathrm{H}$. javanica and $\mathrm{H}$. bpling clades.
\end{abstract}

Keyword: Asian freshwater leech; COI analysis; Coloration patterns; Genetic distance; Hirudinaria 